\title{
UVODNIK
}

\section{MENTORSTVO NEKOČ IN DANES - POMEMBNA OBLIKA IZOBRAŽEVANJA TER PRENOSA ZNANJA IN IZKUŠENJ}

Mentorstvo ni nekaj novega. O njem se je govorilo že v daljni preteklosti, konkretno v antiki, saj iz Platonovih del, ki so nastajala v letih od 427 do 347 pred našim štetjem, spoznamo, da naj bi tudi Platon imel mentorja in velikega učitelja v Sokratu, za katerega je bilo značilno poučevanje z dialogom (Garvey, Stokes in Megginson, 2009). Tudi Platon je nadaljeval vlogo mentorja, in sicer je bil mentor Aristotelu. Ta je začel koncept mentorstva, filozofijo poučevanja, ki izhaja iz obrtniške tradicije za časa Aristotelovega življenja, še bolj razvijati. Prvič je bil izraz mentor omenjen v Homerjevem epu Odiseja, ki opisuje mentorja kot prijatelja, vodnika, varuha in svetovalca Telemaha, Odisejevega sina (prav tam). Odisej, kralj Itake, se je odpravil v trojansko vojno. Kot skrbnika za vzgojo, poučevanje in vodenje svojega sina je izbral pametnega in zaupanja vrednega prijatelja Mentorja. Ta je deloval v vlogi starša, učitelja, prijatelja, vodnika in zaščitnika Odisejevega sina. O tem piše več avtorjev (Daloz, 1986; Parsloe, 1992; Cohen, 1995; Essom, 2003; Keller, 2007, idr.). Garvey idr. (2009) menijo, da je Homerjevo mentorstvo povezano z izkustvenim učenjem, podporo in izzivi, ki jih mentor daje mentorirancu. Parsloe in Leedham (2009) navajata sploh pomen grške literature za razvoj besede mentor, ki naj bi se uporabljala $\mathrm{v}$ krogih takratnih politikov in igralcev. S to besedo so označili, kot omenjata, osebo, ki jim je vzor, ki ima močan vpliv na razvoj kariere druge osebe. Nekateri drugi avtorji, denimo Boreen, Johnson, Niday in Potts (2009), so začetke mentorstva našli celo v 18. stoletju pred našim štetjem, v nastanku sistema vajeništva, ko naj bi babilonski zakoni od obrtnikov zahtevali, da izobrazijo vajence kot svoje naslednike. Tak sistem vajeništva naj bi se skozi zgodovino prijel in izpopolnjeval vse do 20. stoletja našega štetja, ko sta omenjeni model prevzela gospodarstvo in industrija.

Mentorstvo ima torej dolgo tradicijo in ugotovimo lahko, da so se nekatere značilnosti ohranile do danes, na primer da je mentorstvo povezano z dialogom, razvijanjem posameznika, njegovega samozavedanja, kritičnosti, da je mentorstvo vodenje osebe v lastno kariero. Predvsem pa lahko poudarimo, da se je skozi zgodovino razvijal in spreminjal tudi pomen mentorstva. Govekar-Okoliš in Ličen (2008, str. 23) omenjata, da »sodobna družba postavlja v ospredje posameznika, njegovo znanje, zamisli in ideje. Zahteva, da se človek nenehno izobražuje, da lahko preživi, da se razvija in odkriva nove razsežnosti 
svoje osebnosti.« Danes, v sodobni informacijski družbi, prihaja vedno bolj v ospredje posameznik, kot pravi Krajnc (2012), njegovo samostojno izobraževanje, saj današnja družba zahteva čim bolj unikatnega posameznika, ki je samoiniciativen, ustvarjalen in sposoben stalnega osebnega napredovanja ter sprejemanja družbenih novosti. Za primer, kako s pomočjo mentorstva povezati posameznike $\mathrm{v}$ družbi, naj omenimo aktualen dogodek, ko je 26. maja letos Zavod Ypsilon mentorsko povezal Slovenijo in bil pobudnik akcije »Slovenija mentorska država«, kar je potekalo v okviru Tedna vseživljenjskega učenja. Namen akcije je bil omogočiti mladim dostop do mentorjev z različnih področij (podjetništvo, gospodarstvo, umetnost, kultura, šport, politika idr.) in s tem spodbuditi medgeneracijsko povezovanje, izobraževanje in sodelovanje. Cilji so bili pospešiti pretok znanja in informacij med generacijami, ozaveščati o pomenu mentorstva ter krepiti medgeneracijsko sodelovanje. Z akcijo so želeli doseči, »da bi imel vsak vsaj enkrat v življenju mentorja« (Slovenija mentorska država, 2016). Po vsej Sloveniji so potekale delavnice in dogodki, kjer so se mentorji in mentoriranci povezali v mentorske pare: mladi so stik z mentorji vzpostavili prek spletne platforme www.mentorstvo.si (prav tam). Omenjena akcija je primer, kako lahko danes z mentorstvom kot obliko izobraževanja dvigujemo raven zavesti vsakega posameznika in tudi celotne družbe.

Težava se pojavi, ko želimo mentorstvo definirati, saj se srečamo z različnimi opredelitvami. Spoznamo, da gre v grobem za odnos sodelovanja med bolj izkušeno in manj izkušeno osebo, ko izkušenejša oseba uči, svetuje, pomaga z znanjem in izkušnjami manj izkušeni. V literaturi najdemo več opredelitev, kdo je mentor, kakšen je in kaj je mentorski odnos oziroma mentorstvo. Mentor je vodnik, učitelj, vzgojitelj, moder in dobro misleč svetovalec, oseba, ki z nasveti in pojasnili usmerja ter vodi neizkušenega posameznika (Govekar-Okoliš in Kranjčec, 2016). Mentor mentorirancu skrajša pot do cilja in nadomešča nekatere njegove manjkajoče lastnosti (Krajnc, 2012). Megginson, Clutterbuck, Garvey, Stokes in Garrrett-Harris (2006) vidijo mentorja kot strokovno osebo, ki ima modrost in znanje, mentorstvo pa kot zunanjo pomoč mentorja mentorirancu. »Mentorstvo je načrtna pot, proces vodenja, svetovanja, vzajemni dinamičen in diadni odnos med mentorjem in posameznikom. Gre za usmerjanje posameznika z nasveti in pojasnili, v katerem ga mentor vodi, vzgaja, izobražuje, mu svetuje in razvija vedoželjnost ter ga vodi po poti do zastavljenih ciljev.« (Govekar-Okoliš in Kranjčec, 2016, str. 46) Pri mentorstvu je pomembno, da posameznik v mentorskem odnosu razvija in gradi svojo osebnost, pridobiva nova znanja in izkušnje, s tem pa razvija lastno identiteto ter dosega osebne cilje v razvoju svoje kariere. Vsako mentorstvo, ki izhaja iz posameznika, njegovih potreb, želja, interesov, obstoječih izkušenj in znanj ter v procesu diadnega sodelovanja odpira pri mentorirancu nove, neodkrite značilnosti osebnosti in podlage za posameznikovo nadaljnjo rast in razvoj, je učinkovito mentorstvo. Pravimo, da je mentorstvo edinstven odnos med mentorjem in mentorirancem, je učno partnerstvo, $v$ katerem gre za način podpore mentorja mentorirancu in za učinkovit, vzajemen odnos sodelovanja. Mentorstvo pomaga odkrivati kritičnega, samostojnega in ustvarjalnega posameznika, ob tem pomeni tudi pomoč posamezniku pri njegovem razvoju in vključitvi v okolje (prav tam). Mentorstvo je danes zelo pogosta oblika izobraževanja, ki pomeni prenos znanja in izkušenj mentorja na mentoriranca. 
Glede na to, da je osrednja tema tokratnih Andragoških spoznanj mentorstvo, bomo lahko v reviji spoznali več njegovih oblik. Da je mentorstvo v praktičnem usposabljanju danes postalo pomemben sestavni del bolonjskih študijskih programov, izvemo iz prispevka Eve Repe $\mathrm{z}$ naslovom »Proces prenove praktičnega usposabljanja - praktično usposabljanje $\mathrm{v}$ bolonjskih študijskih programih«, v katerem je opisala proces prenove praktičnega usposabljanja na Univerzi v Ljubljani ter opredelila, kakšni so značilnosti in cilji ter strategije praktičnega usposabljanja v bolonjskih študijskih programih članic Univerze v Ljubljani.

Prav tako je o pomenu mentorstva na praktičnem usposabljanju pisala Helena Mesarič, ki je poudarila pomen varovanja zdravja praktikantov na praktičnem usposabljanju. V svojem prispevku »Kako mladim delavcem približati varnost in zdravje pri usposabljanju za delo« je opisala, kako danes mladim delavcem približati varnost in kako skrbeti za zdravje pri usposabljanju za delo. Po podatkih Evropske skupnosti ugotavlja, da je populacija mladih v starosti od 18 do 24 let zaradi pomanjkanja izkušenj in znanja o varnosti in zdravju pri delu posebej ogrožena. Zato je v mentorstvu na praktičnem usposabljanju pri delu nujno zagotoviti varnost in zdravje.

Zanimiv je tudi prispevek z naslovom »Pogledi mentorjev in študentov zdravstvene nege na praktično usposabljanje «, ki obravnava praktično usposabljanje študentov zdravstvene nege. Predstavljene so bistvene značilnosti tovrstnega mentorstva v kliničnem okolju, ki je obvezen del bolonjskega študijskega programa. Kot zanimivost avtorici Nataša Kermavnar in Monika Govekar-Okoliš odkrivata razlike v pogledih mentorjev in študentov na usposabljanje v kliničnem okolju ter njihova pričakovanja do dela v praksi. Njuna raziskava je pokazala, katere izboljšave pri sodelovanju med mentorji in praktikanti so potrebne, in ponudila predloge za izboljšanje mentorstva $\mathrm{v}$ zdravstveni negi.

Prispevek »O mentorstvu v Slovenskem šolskem muzeju« v Ljubljani je pripravila Marjetka Balkovec Debevec, ki je opisala področje mentorstva v praktičnem usposabljanju v muzeju. Spoznamo, da ima muzej pomembno izobraževalno vlogo tudi prek mentorstva, in to na različnih ravneh dela. $\mathrm{Z}$ mentorstvom $\mathrm{v}$ praktičnem usposabljanju se danes $\mathrm{v}$ muzeju dopolnjuje poslanstvo kustosov tudi kot mentorjev. Avtorica v svoji raziskavi odkriva značilnosti mentorstva v praktičnem usposabljanju v muzeju po uvedbi bolonjskih študijskih programov na članicah Univerze v Ljubljani, ki pošiljajo študente na prakso. Ugotavlja, katere so novosti in izboljšave v mentorstvu, ter v ospredje postavlja pomen izobraževanja mentorjev za vodenje prakse študentov v muzeju.

Nekoliko drugačno mentorstvo spoznamo v prispevku Katje Palčič z naslovom »Vloga mentorja pri umetniškem ustvarjanju v skupini odraslih z motnjo v duševnem razvoju «. Opisala je značilnosti mentorstva v skupini odraslih oseb z motnjo v duševnem razvoju na podlagi ugotovitev raziskave, v kateri je odkrivala različne vloge mentorja pri umetniškem ustvarjanju v skupini odraslih z motnjo v duševnem razvoju.

Prispevek »Social Images of Youth as a Challenge for Mentoring Work « je pripravila Katja Jeznik. Z raziskavo je ugotavljala, kako se predstave o mladih odražajo v podobi o dijakih poklicnih šol, in sicer glede na ocene učiteljev in dijakov. Pri tem je poudarila 
vlogo mentorjev na praktičnem usposabljanju dijakov v organizacijah, katerim je v izziv, da izboljšajo podobo mladih in jih vodijo v poklic.

Prispevek, ki se ne ukvarja z mentorstvom, je tematsko nadaljevanje teme o neoliberalizmu iz prejšnje številke AS. Primož Krašovec v prispevku z naslovom »Še enkrat o neoliberalizmu III: Psihoafektivni učinki neoliberalizma in neoliberalna subjektivnost « V ospredje postavlja delovanje neoliberalizma na mikrosocialni ravni in na ravni individualne psihologije. Dotakne se današnjega problema neoliberalne ekonomije, ki ima velik vpliv na podjetja in na posameznika, pri tem pa neoliberalizem predstavi kot posebno etiko vsakdanjega življenja.

Tokratno številko zapiramo s predstavitvijo tuje knjige, ki jo je pripravila Jasna Fakin Bajec. Gre za delo z naslovom »Researching and Transforming Adult Learning and Communities«, ki so ga uredili Rob Evans, Ewa Kurantowicz in Emilio Lucio-Villegas, izdalo pa Evropsko združenje raziskovalcev izobraževanja odraslih. V njem avtorji in avtorice, ki prihajajo iz različnih geografskih okolij (Švica, Belgija, Poljska, Španija, Portugalska, Škotska, Kanada, Mehika), predstavljajo raznolike raziskave, ki se ukvarjajo s tematiko vključenosti ljudi v transformativno učenje v skupnosti, pišejo o re-lokaciji družbenega učenja kot demokratični praksi, s čimer je povezano tudi vse bolj pomembno participatorno akcijsko raziskovanje in izobraževanje vseh vključenih.

\section{Monika Govekar-Okoliš}

\section{LITERATURA}

Boreen, J., Johnson, M. K., Niday, D. in Potts, J. (2009). Mentoring Beginning Teachers: Guiding, Reflecting, Coaching. Portland: Stenhouse.

Cohen, N. H. (1995). Mentoring adult learners: a guide for educators and trainers. Malabar: Krieger.

Daloz, L. A. (1986). Effective Teaching and mentoring: Realizing the Transformational Power of Adult Learning Experiences. San Francisco: Jossey-Bass.

Essom, J. (2003). ICT Mentors. Leicester: National Institute of Adult Continuing education.

Garvey, R., Stokes., P. in Megginson D. (2009). Coaching and Mentoring: Theory and Practice. London: SAGE.

Govekar-Okoliš, M. in Kranjčec, R. (2016). Mentorstvo v praktičnem usposabljanju v delovnih organizacijah. Ljubljana: Znanstvena založba Filozofske fakultete.

Govekar-Okoliš, M. in Ličen, N. (2008). Poglavja iz andragogike. Ljubljana: Znanstvena založba Filozofske fakultete, Oddelek za pedagogiko in andragogiko.

Keller, T. E. (2007). Youth Mentoring: Theoretical and Methodological Issues. V T. D. Allen in L. T. Eby (ur.), The Blackwell handbook of mentoring: a multiple perspective approach (str. 23-47). Malden: Blackwell.

Krajnc, A. (2012). Individualizacija izobraževanja vodi v mentorsko gibanje »Znaš, nauči drugega«. Andragoška spoznanja, 18(2), 19-30.

Megginson, D., Clutterbuck, D., Garvey, B., Stokes, P. in Garrett-Harris, R. (2006). Mentoring in Action: a practical guide. London: Kogan Page. 
Parsloe, E. (1992).Coaching Mentoring and Assessing: A Practical Guide to Developing Competence. London: Kogan Page.

Parsloe, E. in Leedham, M. (2009). Coaching and Mentoring: Practical conversation to improve learning. London: Kogan Page.

Slovenija mentorska država (2016). Pridobljeno s https://www.mentorstvo.si/sl/novice/tudi_letos_ mentorsko_povezujemo_slovenijo_bodite_zraven. 